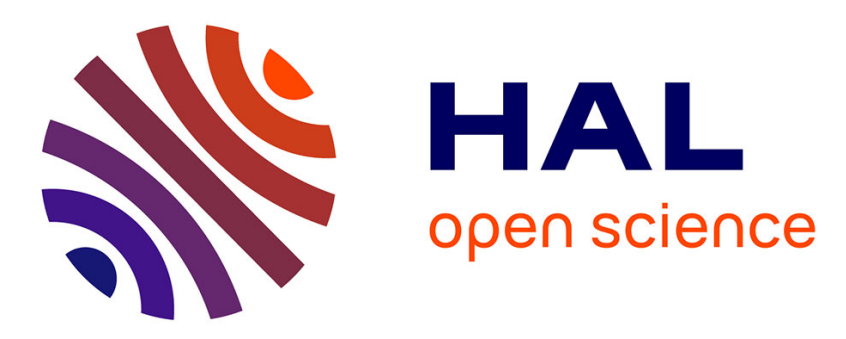

\title{
Ni/Photoredox-Dual-Catalyzed Functionalization of 1-Thiosugars
}

\author{
Mingxiang Zhu, Guillaume Dagousset, Mouad Alami, Emmanuel Magnier, \\ Samir Messaoudi
}

\section{- To cite this version:}

Mingxiang Zhu, Guillaume Dagousset, Mouad Alami, Emmanuel Magnier, Samir Messaoudi. Ni/Photoredox-Dual-Catalyzed Functionalization of 1-Thiosugars. Organic Letters, 2019, 21 (13), pp.5132-5137. 10.1021/acs.orglett.9b01730 . hal-02396639

\section{HAL Id: hal-02396639 \\ https://hal.science/hal-02396639}

Submitted on 6 Dec 2019

HAL is a multi-disciplinary open access archive for the deposit and dissemination of scientific research documents, whether they are published or not. The documents may come from teaching and research institutions in France or abroad, or from public or private research centers.
L'archive ouverte pluridisciplinaire HAL, est destinée au dépôt et à la diffusion de documents scientifiques de niveau recherche, publiés ou non, émanant des établissements d'enseignement et de recherche français ou étrangers, des laboratoires publics ou privés. 


\title{
Ni/Photoredox-Dual-Catalyzed Functionalization of 1- Thiosugars
}

\author{
Mingxiang Zhu, ${ }^{\mathrm{a}}$ Guillaume Dagousset, ${ }^{\mathrm{b}}$ Mouad Alami, ${ }^{\mathrm{a}}$ Emmanuel Magnier ${ }^{\mathrm{b}}$ and Samir \\ Messaoudi ${ }^{\mathrm{a}^{*}}$ \\ ${ }^{a}$ BioCIS, Univ. Paris-Sud, CNRS, University Paris-Saclay, Châtenay-Malabry, France \\ ${ }^{\mathrm{b}}$ Institut Lavoisier de Versailles, UMR 8180, Université de Versailles Saint-Quentin 78035 Versailles Cedex, France \\ Supporting Information Placeholder
}

In memory of Professor François Couty.

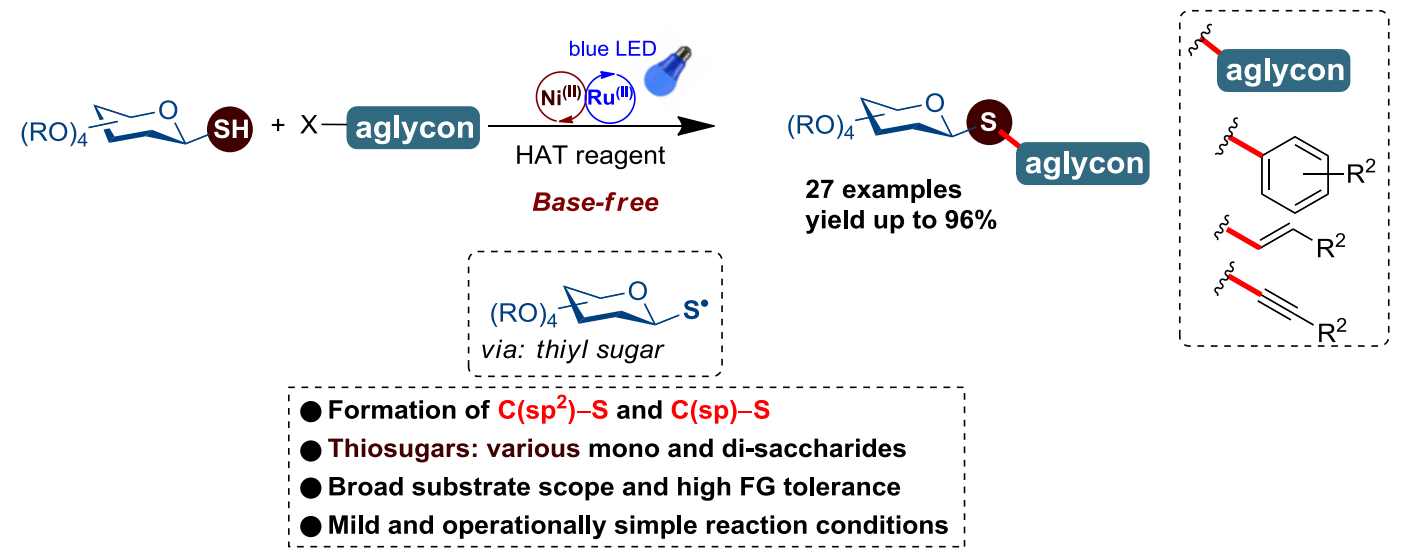

ABSTRACT: A general protocol for functionalization of glycosyl thiols has been reported. This protocol is based on a single-electron $\mathrm{Ni}$ /photoredox dual-catalyzed cross-coupling between 1-thiosugars and a broad range of arylbromides and iodides as well as alkenyl and alkynyl halides. This base-free method gives access to a series of functionalized thioglycosides in moderate to excellent yields with a perfect control of the anomeric configuration. Moreover, it has been shown that this methodology may be transposed successfully to the continuous-flow photoredox chemistry.

1-Thioglycosides are of great interest in pharmaceutical science. ${ }^{[1]}$ These derivatives are considered as mimetics of biologically relevant $O$-glycosides as they are known to be resistant towards enzymatic hydrolysis. ${ }^{[2]}$ Some biologically active 1-thioglycosides are represented in Figure 1, including hSGLT1 inhibitor, ligand of lectine A, cytotoxic Hsp9o inhibitor, galactosidase and glycosidase inhibitors, as well as antimicrobial agent. In addition, thioglycosides are considered as a versatile intermediates in organic synthesis. ${ }^{[3]}$

Despite their potential interest in medicinal chemistry, only few methods report their synthesis. Usually, they are prepared by reaction of thiophenol with a per-O-acetylated glycosyl donors in the presence of a Lewis acid. ${ }^{[4]}$ They also could be prepared by substituting the halogen atom at the anomeric position of the sugar by a thiolate anion. ${ }^{\left[{ }^{5]}\right.}$ These approaches however suffer from the harsh reaction conditions, and are limited in substrate scope with thiophenols. Various $\mathrm{Pd}-{ }^{[6]} \mathrm{Ni}_{-}{ }^{[7]}$ or Cu-catalyzed ${ }^{[8]}$ S-arylations of glycosyl thiols with aryl iodides were developed independently by Sticha, Xue, and our group (figure 2 Ia-b). ${ }^{[9]}$
However, demanding reaction conditions such as high catalyst loadings ( $30 \mathrm{~mol} \%$ in the case of $\mathrm{Ni}$-catalysis), specialized phosphine ligands for the Pd- catalysis, elevated reaction temperatures $\left(80-120^{\circ} \mathrm{C}\right.$ cases of $\mathrm{Pd}-$ or $\mathrm{Cu}-$

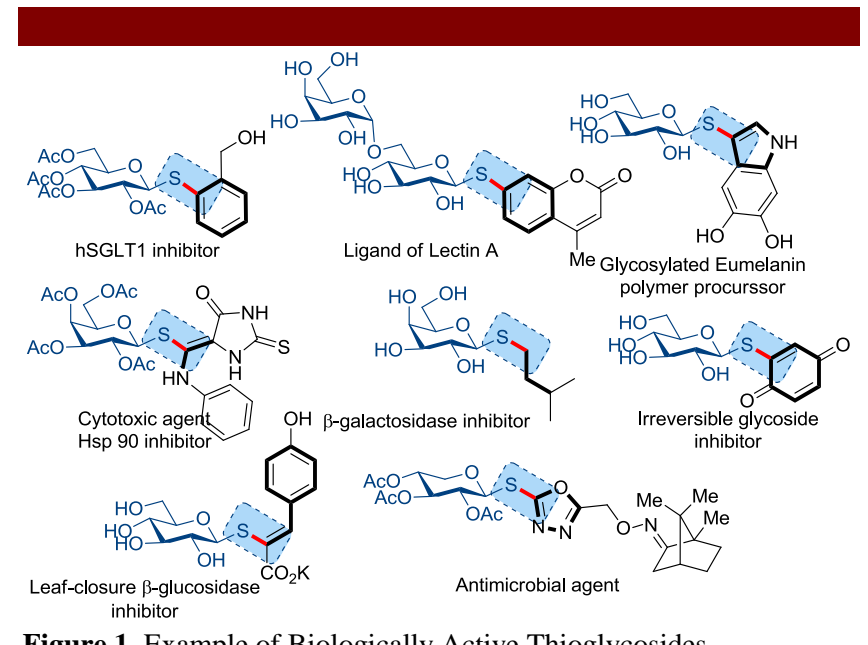

Figure 1. Example of Biologically Active Thioglycosides 
catalysis), and long reaction times often limit the practicability or the scope of substrates. Moreover, in all these cases the coupling is effective with only aryl iodides, how- ever the cross-coupling with aryl bromides is rather unexplored.

(I) Metal catalyzed cross-couplings

a) Buchwald-Hartwig-Migita coupling

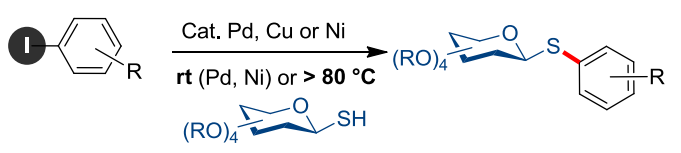

b) $\mathrm{C}\left(\mathrm{sp}^{2}\right)-\mathrm{H}$ thioarylation

c) This work: Ni/photoredox-dual catalysis

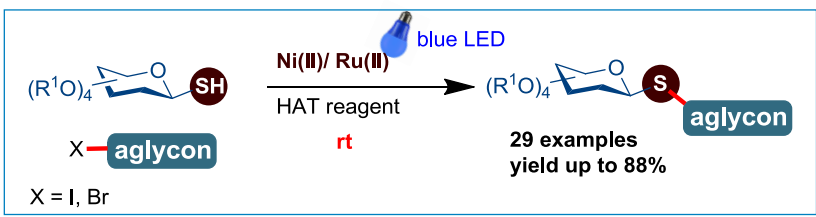

(II) Proposed mechanism pathway and catalyst combination
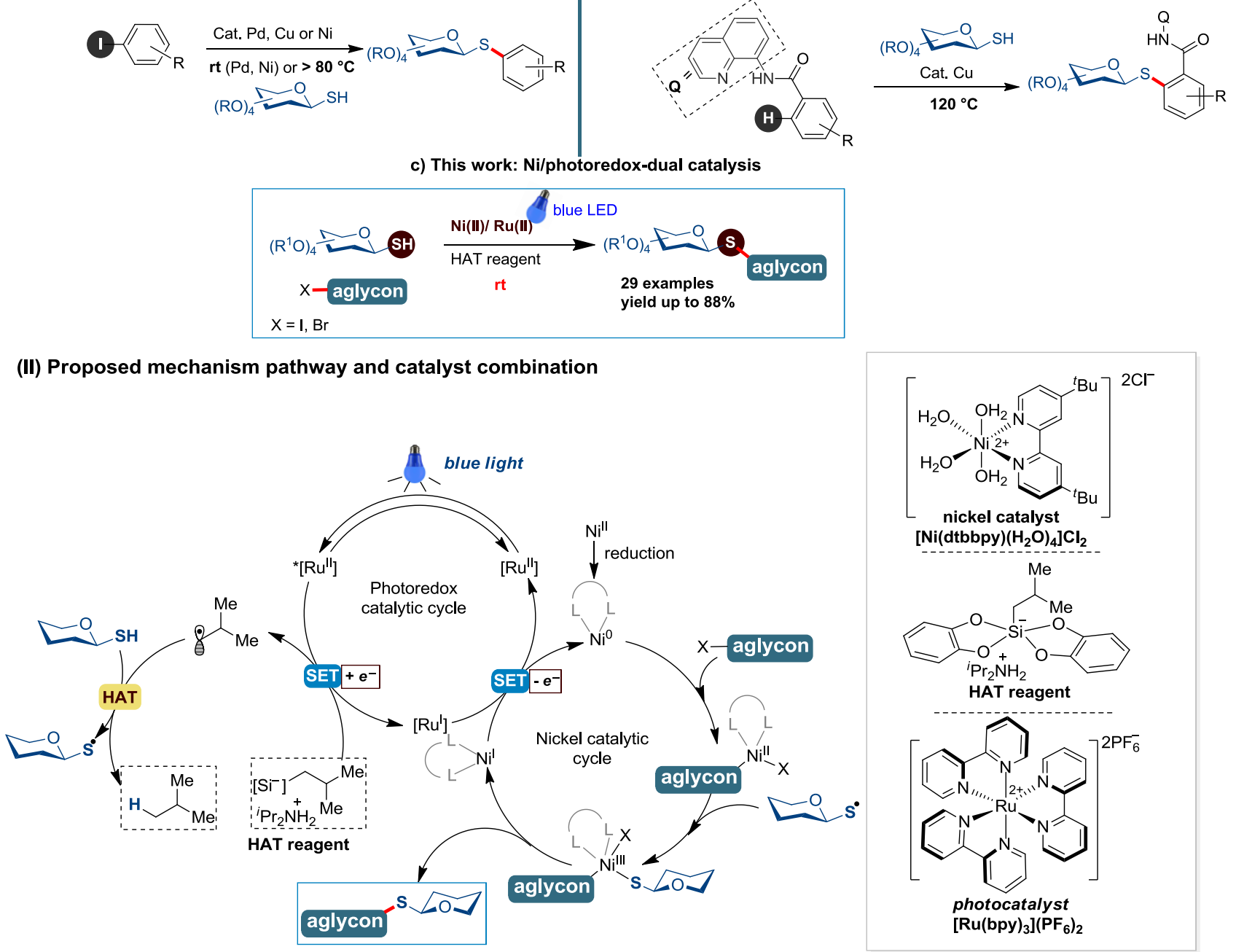

b) $\mathrm{C}\left(\mathrm{sp}^{2}\right)-\mathrm{H}$ thioarylation
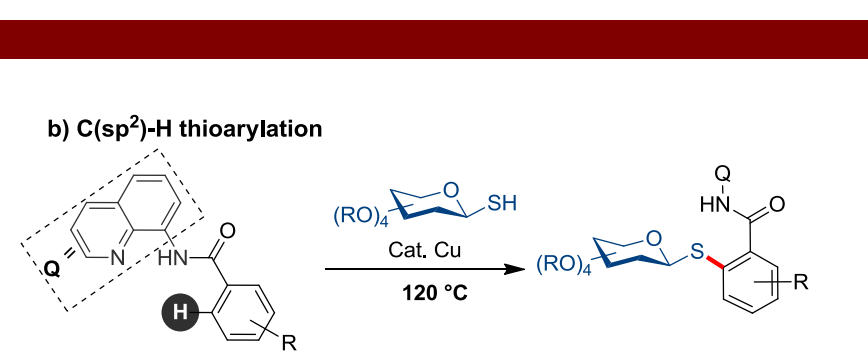
processes. ${ }^{\left[{ }_{13}\right]}$ Rapid H-atom abstraction from the glycosyl sulfhydryl group generates a glycosyl thiyl radical. This later adds to $\mathrm{Ni}$ (II) which arises from $\mathrm{Ni}(\mathrm{o})$ oxidative addition with the aglycon halide. In a possible alternative of the catalytic cycle, Molander, Kozlowski and co-workers reported that the thiyl radical metalation may precede the oxidative addition step. ${ }^{[14]}$ Reductive elimination from $\mathrm{Ni}$ (III) affords the desired thioglycoside, and the dual catalytic cycles are closed by a final SET.

In the first set of experiments, we examined the coupling of tetra- $O$-acetylated 1-thio- $\beta$-D-glucopyranose ra with 1bromobenzonitrile $\mathbf{2 a}$ as a model study under various reaction conditions. Representative results from this study are summarized in Table 1 . The reaction of $1 \mathbf{1 a}(1$ equiv) with 2a (1 equiv) was first investigated under the Molander's conditions using $5 \mathrm{~mol} \%$ of $\left[\mathrm{Ni}(\mathrm{dtbbpy})\left(\mathrm{H}_{2} \mathrm{O}\right)_{4}\right] \mathrm{Cl}_{2}, 2 \mathrm{~mol} \%$ of a commercially available $\left[\mathrm{Ru}(\mathrm{bpy})_{3}\left(\mathrm{PF}_{6}\right)_{2}\right]$ photocatalyst in the presence of ammonium bis(catechol)alkyl silicate (1.3 equiv) as a HAT reagent under blue light emitting diode (LED) irradiation (Table 1, entry 1). Pleasingly, this protocol afforded the desired thioglycoside $3 \mathbf{a}$ in a moderate $59 \%$ yield as a single $\beta$-anomer $\left(J_{1,2}=9 \mathrm{~Hz}\right)$. Increasing the amount of the bromide partner $\mathbf{2 a}$ from 1 equiv to 1.3 equiv furnished 3 a in a good $79 \%$ yield (entry 2 ). Moreover, the yield was increased up to $85 \%$ yield when 1.5 equiv of 2a were used (entry 3 ). The optimization of the reaction conditions was continued with respect to solvent, however, no significant improvement of the yield of za was observed with DMA, DMSO, MeCN and THF (entries 5-8). Finally, performing the coupling reaction with the iodobenzonitrile instead the bromide led to $3 a$ in $90 \%$ yield (entry 9). Extensive examinations of the other reaction parameters revealed that the use of molecular sieves plays an important role in this reaction. The yield of za was improved up to $95 \%$ with complete retention of the anomeric configuration when the reaction was conducted in the presence of molecular sieves (entry 10). A control experiments showed that all parameters (Ni-catalyst, $\mathrm{Ru}-$ photocatalyst, HAT reagent and light) were essential for the reaction to proceed. Without one of them, the reaction don't occur.

Table 1 Optimization of the Coupling Reaction of $1 \mathbf{a}$ with $\mathbf{2} \mathbf{a}^{a}$

\begin{tabular}{|c|c|c|c|c|}
\hline (1a) 1 equiv & & $\begin{array}{r}\mathrm{Ni}(\mathrm{II}) \text { cat. } \\
{\left[\begin{array}{r}\left.\mathrm{Ru}(\mathrm{bpy})_{3}\right](\mathrm{PF} \\
\text { HAT reagen }\end{array}\right.} \\
\begin{array}{r}\text { Blue LED } \\
\text { DMF, }\end{array}\end{array}$ & $\begin{array}{l}\text { 6) } \\
\text { lol \%) } \mathrm{AcC} \\
\text { (uiv) } \mathrm{AcO} \\
\underset{\mathrm{n})}{\longrightarrow} \mathrm{AcC}\end{array}$ & 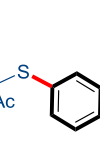 \\
\hline entry & $\mathrm{X}$ & equiv of $\mathbf{2 a}$ & solvant & $3 \mathbf{a}(\%)^{b}$ \\
\hline 1 & $\mathrm{Br}$ & 1 & DMF & 59 \\
\hline 2 & $\mathrm{Br}$ & 1.3 & DMF & 79 \\
\hline 3 & $\mathrm{Br}$ & 1.5 & DMF & $85^{c}$ \\
\hline 4 & $\mathrm{Br}$ & 2 & DMF & 81 \\
\hline 5 & $\mathrm{Br}$ & 2 & DMA & 32 \\
\hline 6 & $\mathrm{Br}$ & 2 & DMSO & 54 \\
\hline 7 & $\mathrm{Br}$ & 2 & $\mathrm{MeCN}$ & 40 \\
\hline 8 & $\mathrm{Br}$ & 2 & THF & 19 \\
\hline 9 & I & 1.5 & DMF & 90 \\
\hline 10 & I & 1.5 & DMF & $95^{d}$ \\
\hline
\end{tabular}

${ }^{a} \mathrm{~A}$ sealable tube was charged with thiosugar $1 \mathrm{a}$ (1 equiv, $0.2 \mathrm{mmol}$ ), 1-bromo-4-benzonitrile $2 \mathrm{a}$ (xx equiv), $\left[\mathrm{Ni}(\mathrm{dtbbpy})\left(\mathrm{H}_{2} \mathrm{O}\right)_{4}\right] \mathrm{Cl}_{2}$ precatalyst $(5 \mathrm{~mol} \%),\left[\mathrm{Ru}(\mathrm{bpy})_{3}\right]\left(\mathrm{PF}_{6}\right)_{2}(2 \mathrm{~mol} \%)$, HAT reagent (diisopropylammonium bis(catechol)isobutylsilicate) (1.3 equiv) in dry and degassed DMF $(1.0 \mathrm{~mL}){ }^{b}$ Yield of isolated product. ${ }^{c} 70 \%$ of $\mathbf{3 a}$ when $3 \mathrm{~mol} \%$ of Ni-catalyst were used. ${ }^{d} 150 \mathrm{mg}$ of molecular sieves were added.

With these encouraging results, we investigated next, the scope for this dual $\mathrm{Ni}$ /photocatalysis process by systematically varying the nature of the electrophile partner 2 and the thiosugar substrates ra-e (Scheme 1). All the coupling proceeded cleanly and selectively in good yields. As showed in Scheme 1, various electron-deficient and electron-rich aryl iodides having para- and meta-substitution effectively underwent reaction with tetra-O-acetylated 1thio- $\beta$-D-glucopyranose $1 \mathrm{a}$ in yields up to $96 \%$ (products 3a-o).

Scheme 1 Scope of Coupling of Thioglucose 1a with Halo(hetero)arenes, Alkenyl Halides and Alkynyl Bromides 2 

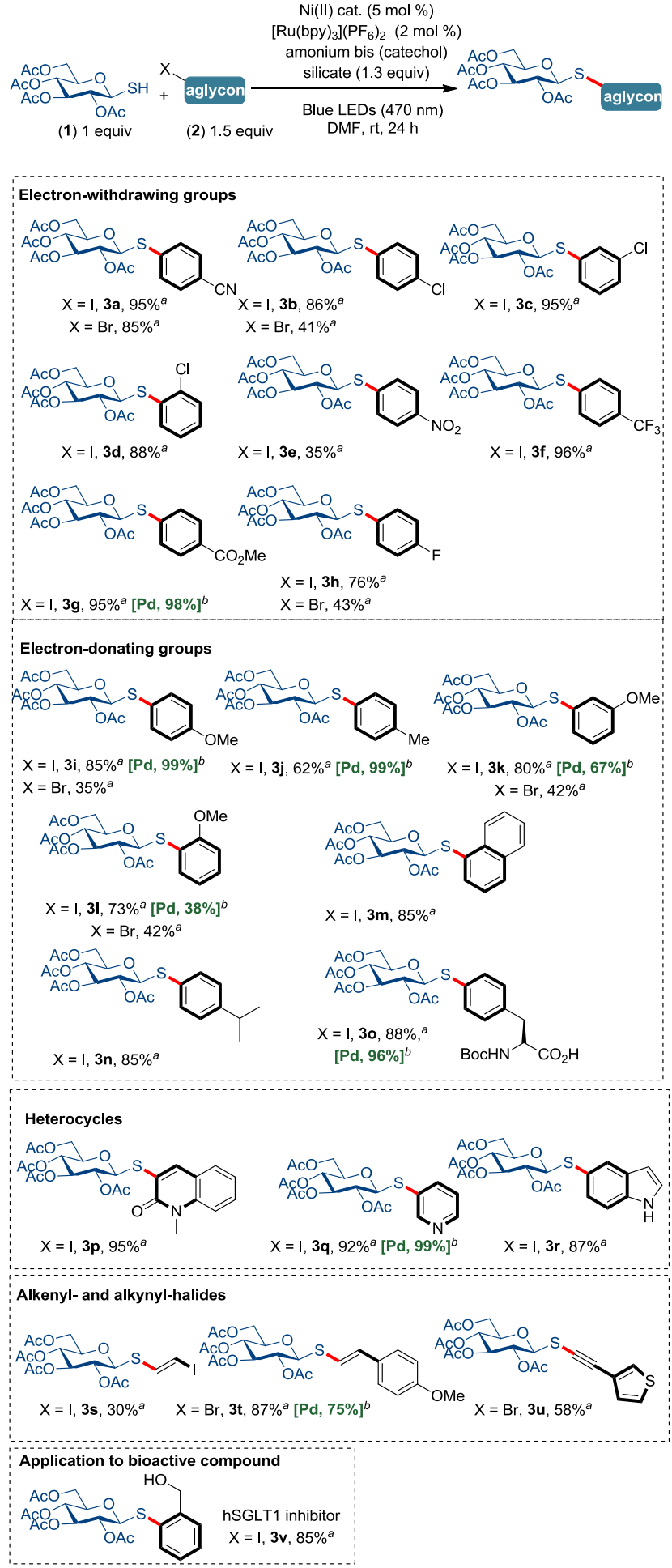

Reaction conditions: A sealable tube was charged with thiosugar 1a (1 equiv, $0.2 \mathrm{mmol})$, aryl, alkenyl, or alkynyl halides $2(1.5$ equiv), $\left[\mathrm{Ni}(\mathrm{dtbbpy})\left(\mathrm{H}_{2} \mathrm{O}\right)_{4}\right] \mathrm{Cl}_{2}$ precatalyst $(5 \mathrm{~mol} \%)$, $\left[\mathrm{Ru}(\mathrm{bpy})_{3}\right]\left(\mathrm{PF}_{6}\right)_{2}$ (2 mol\%), HAT reagent (diisopropylammonium bis(catechol)isobutylsilicate) (1.3 equiv) in dry and degassed DMF (1.0 mL). ${ }^{a}$ Yield of isolated product. ${ }^{b}$ Comparison with results obtained by Pd-catalysis reported in Ref. [7a, 7b and 7c].

Various reactive functional groups were tolerated, such as nitrile (3a), ester (39), halogens (3b-d, $\mathbf{3} \mathbf{h}$ ), isopropyl (3n) and aminoacid (3o). In addition, the presence of an ortho substitution at the aromatic ring of the coupling partner don't affect the coupling process as compounds $\mathbf{3} \mathbf{d}, \mathbf{3} \mathbf{l}$ and
$3 \mathrm{~m}$ having an ortho substituent groups were obtained in $88 \%, 73 \%$ and $85 \%$ yields, respectively.

Aside from aryl iodides, aryl bromides can also serve as coupling partners under Ni-photocatalysis. For example, cross-coupling of aryl bromides bearing various functions $(-\mathrm{CN},-\mathrm{Cl},-\mathrm{F}$ and $-\mathrm{OMe})$ have been successfully achieved under room temperature to afford the corresponding thioglycosides (3a-b, $\mathbf{3} \mathbf{h}, \mathbf{3} \mathbf{i}, \mathbf{3} \mathbf{k}, \mathbf{l})$ in moderate to good yields with no changes to the standard reaction conditions. However, we can note that aryl bromides are less reactive than their iodide congeners in this cross-coupling protocol. Interestingly, couplings with heteroaryl halides derived from quinolinone, pyridine, and indole have also been successful, furnishing $3 \mathbf{p}-\mathbf{r}$ in excellent yields $(87 \%$ to 95\%). In addition, para-iodophenylalanine (NHBoc) can be employed as a coupling partner (compound 30).

One can be note that across a number of substrates, coupling products were afforded in comparable yields to those obtained under palladium-catalyzed (thermal) conditions.

In the aim to further pushing the limit of this $\mathrm{Ni}$ photocatalysis protocol, we examined the coupling of $\mathbf{1 a}$ with halogenated alkenes and alkynes. Delightfully, when $E$ - $\beta$-styryl bromide was employed, the coupling with ra afforded stereoselectively the desired alkenyl thioglycoside derivative 3 t in $87 \%$ yield. In addition, reaction of $4^{-}$ (bromoethynyl)thiophene with ra furnished the desired alkynyl-thioether $3 \mathbf{u}$ in a $58 \%$ yield. Interestingly, when (E)-1,2-diiodoethene was used, the coupling reaction with 1a furnished selectively the monocoupling product $3 \mathrm{~s}$ in a moderate $30 \%$ yield, while the formation of di-coupling product has never been observed. Finally, this methodology was applied with success to the synthesis of the compound $3 \mathbf{v}$ ( $85 \%$ yield), an hSGLT1 inhibitor used for the control of hyperglycemia in patients with diabetes.

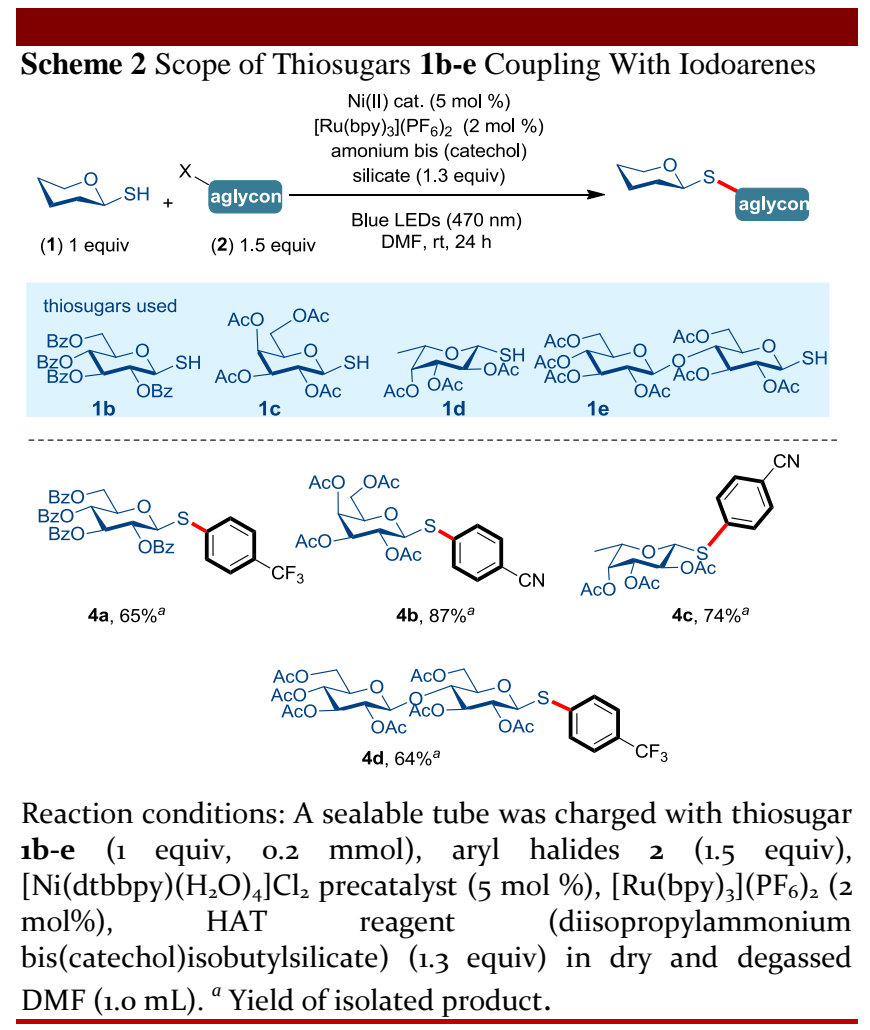

In a next step, we examined the scope of this method with respect to the glycosyl thiols. As depicted in Scheme 2, this 
coupling reaction tolerates different glycosylthiols $\mathbf{1 b}$-e: $O$ benzoylated 1-thio- $\beta$-D-glucopyranose $\mathbf{1 b} O$-acetylated 1 thio- $\beta$-D-galactopyranose 1c and $O$-acetylated 1-thio- $\beta$-Dfucopyranose $\mathbf{1 d}$ all coupled with the 4-iodobenzonitrile $\mathbf{2 a}$ to give thioglycosides $\mathbf{4 a - c}$ in good yields. In addition, this coupling could be applied to the complex disaccharide 1thio- $\beta$-D-cellobiose 1e which was efficiently reacted with $2 a$ to give $4 \mathrm{~d}$ in $64 \%$ yield.

Recently, continuous flow synthetic methodologies combined to photochemistry have become an emerging field. ${ }^{[15]}$ This combination could allow the development of fully automated process with an increased efficiency and, in many cases, improved sustainability. The great peculiarity of a flow photoredox system is a very efficient irradiation that allows to speed the reaction rate up so that productivity is generally greatly improved with respect to the batch system. Indeed, reaction scale up is usually easy to perform with high yields. In order to accelerate our coupling process, we attempted to transporte the continuous-flow techniques to our reaction. We were pleased to see that the thioarylation of 1a with $\mathbf{2 a}$ in a large-scale version ( 0.8 mmol scale, 4 fold), could be carried out under the same conditions at a residence time of $20 \mathrm{~min}$ at $25^{\circ} \mathrm{C}$. Remarkably, the reaction runs smoothly with complete conversion and the desired product was isolated in $79 \%$ yield (Scheme 3).

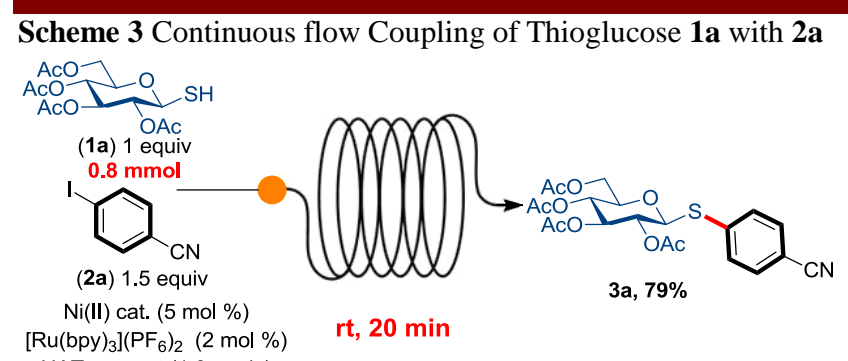

In summary, we have shown that 1-thiosugars are competent nucleophile partners in the $\mathrm{Ni} /$ photoredox-dualcatalyzed cross-coupling reactions, and developed a general method for the synthesis of thioglycosides in batch or in flow. The method tolerates a wide range of functional groups such as aryl, heteroaryl, alkenyl and alkynyl bromides and iodides. In addition, a variety of glycosyl thiols could be used. This method opens news opportunities for using thiosugars in synthetic methodology.

\section{ASSOCIATED CONTENT}

\section{Supporting Information}

The Supporting Information is available free of charge on the ACS Publications website.

Experimental procedures, spectroscopic data and NMR spectra of new compounds.

\section{AUTHOR INFORMATION}

\section{Corresponding Author}

*E-mail: samir.messaoudi@u-psud.fr

\section{Author Contributions}

The manuscript was written through contributions of all authors. / All authors have given approval to the final version of the manuscript.

\section{Notes}

The authors declare no competing financial interest.

\section{ACKNOWLEDGMENTS}

Authors acknowledge support of this project by CNRS, University Paris-Sud, ANR (CarNuCat, ANR-15-CE29- 0002), and by la Ligue Contre le Cancer through an Equipe Labellisée 2014 grant. We also thank the China Scholarship Council for a fellowship (CSC) to Mingxiang Zhu. The laboratory of Châtenay-Malabry is a member of the Laboratory of Excellence LERMIT supported by a grant (ANR-10-LABX-33). The laboratory of Versailles is a member of the Laboratory of Excellence CHARMMMAT which is acknowledge for the funding of the flow chemistry device.

\section{REFERENCES}

(1) (a) For general reviews, see: a) Driguez, H. Thiooligosaccharides in glycobiology. Glycoscience Synthesis Of Substrate Analogs And Mimetics. 1997, 187, 85; b) Witczak, Z. J. Thio sugars: biological relevance as potential new therapeutics. Curr. Med. Chem. 1999, 6, 165; c) Pachamuthu, K.; Schmidt, R. R. Synthetic routes to thiooligosaccharides and thioglycopeptides. Chem. Rev. 2006, 106, 16o; d) Samuni-Blank, M.; Izhaki, I.; Dearing, M. D.; Gerchman, Y.; Trabelcy, B.; Karasov, A. L. W. H.; Arad, Z. Intraspecific Directed Deterrence by the Mustard Oil Bomb in a Desert Plant. Curr. Biol. 2012, 22, 1218; e) Lian, G.; Zhang, X.; Yu, B. Thioglycosides in carbohydrate research. Carbohydr. Res. 2015, 403, 13. For Selected articles: f) Castaneda, F.; Burse, A.; Boland, W.; Kinne, R. K. H. Thioglycosides as inhibitors of hSGLT1 and hSGLT2: potential therapeutic agents for the control of hyperglycemia in diabetes. Int. J. Med. Sci. 2007, 4, 131; g) Rodrigue, J.; Ganne, G.; Blanchard, B.; Saucier, C.; Giguere, D.; Shiao, T. C.; Varrot, A.; Imberty, A.; Roy, R. Aromatic thioglycoside inhibitors against the virulence factor LecA from Pseudomonas aeruginosa. Org. Biomol. Chem. 2013, 11, 6906; h) Elgemeie, G. H.; Farag, A. B.; Amin, K. M.; El-Badry, O. M.; Hassan, G. S. Design, synthesis and cytotoxic evaluation of novel heterocyclic thioglycosides. Med. Chem. 2014, 4, 814; i) Aouad, M. R. Synthesis and Antimicrobial Screening of Novel Thioglycosides and Acyclonucleoside Analogs Carrying 1, 2, 3-Triazole and 1, 3, 4-Oxadiazole Moieties. Nucleos. Nucleot. Nucl. 2016, 35, 1; j) Kato, E.; Nagano, H.; Yamamura, S.; Ueda, M. Synthetic inhibitor of leaf-closure that reveals the biological importance of leaf-movement for the survival of leguminous plants. Tetrahedron, 2003, 59, 5909; k) Schnabelrauch, M.; Vasella, A.; Withers, S. G. Synthesis and Evaluation as Irreversible Glycosidase Inhibitors of Mono- and Oligo(glycosylthio)benzoquinones. Helv. Chim. Acta. 1994, 77, 778; 1) Adinolfi, M.; d'Ischia, M.; Iadonisi, A.; Leone, L.; Pezzella, A.; Valerio, S. Glycosylated Eumelanin Building Blocks by Thioglycosylation of 5, 6-Diacetoxyindole with an Expedient Selenium-Based Dynamic-Mixture Methodology. Eur. J. Org. Chem. 2012, 23, 4333; m) Shirota, K.; Kato, Y.; Suzuki, K.; Sugiyama, Y. Characterization of Novel Kidney-Specific Delivery System Using an Alkylglucoside Vector. J. Pharmacol. Exp. Ther. 2001, 299, 459; n) Caraballo, R.; Sakulsombat, M.; Ramstrçm, O. Towards Dynamic Drug Design: Identification and Optimization of $\beta$-Galactosidase Inhibitors from a Dynamic Hemithioacetal System. ChemBioChem 2010, 11, 1600.

(2) a) Rye, C. S.; Withers, S. G. The synthesis of a novel thiolinked disaccharide of chondroitin as a potential inhibitor of polysaccharide lyases. Carbohydr. Res. 2004, 339, 699; b) Metaferia, B. B.; Fetterolf, B. J.; Shazad-ul-Hussan, S.; Moravec, M.; Smith, J. A.; Ray, S.; Gutierrez-Lugo, M.-T.; Bewley, C. A. 
Synthesis of Natural Product-Inspired Inhibitors of Mycobacterium tuberculosis Mycothiol-Associated Enzymes: The First Inhibitors of GlcNAc-Ins Deacetylase. J. Med. Chem. 2007, 50, 6326; c) Castaneda, F.; Burse, A.; Boland, W.; Kinne, R. K.-H. Thioglycosides as inhibitors of hSGLT1 and hSGLT2: Potential therapeutic agents for the control of hyperglycemia in diabetes. Int. J. Med. Sci. 2007, 4, 131.

(3) a) Codee, J. D. C.; Litjens, R. E. J. N.; van den Bos, L. J.; Overkleeft, H. S.; van der Marel, G. A. Thioglycosides in sequential glycosylation strategies. Chem. Soc. Rev. 2005, 34, 769; for selected examples, see: b) Johannes, M.; Reindl, M.; Gerlitzki, B.; Schmitt, E.; Hoffmann-Rçder, A. Synthesis and biological evaluation of a novel MUC 1 glycopeptide conjugate vaccine candidate comprising a 4'-deoxy-4'-fluoro-ThomsenFriedenreich epitope. Beilstein J. Org. Chem. 2015, 11, 155; c) Budhadev, D.; Mukhopadhyay, B. Synthesis of two trisaccharides related to the hepatoprotective phenylethanoids leonoside $\mathrm{E}$ and F isolated from Leonurus japonicus Houtt. Carbohydr. Res. 2014, 384, 51; d) Basu, N.; Kumar Maity, S.; Ghosh, R. Trichloroisocyanuric acid (TCCA)-TMSOTf: an efficient activator system for glycosylation reactions based on thioglycosides. RSC Adv. 2012, 2, 12661; e) Verma, P.; Raj, R.; Roy, B.; Mukhopadhyay, B. Synthesis of a tetrasaccharide related to the triterpenoid saponin isolated from Schima noronhae. Tetrahedron: Asymmetry 2010, 21, 2413; f) D. Xiong, C.; Zhang, L. H.; Ye, X. S. Bromodimethylsulfonium Bromide - Silver Triflate: A New Powerful Promoter System for the Activation of Thioglycosides. Adv. Synth. Catal. 2oo8, 350, 1696; g) Roy, B.; Pramanik, K.; Mukhopadhyay, B. Synthesis of a tetra- and a trisaccharide related to an anti-tumor saponin "Julibroside $\mathrm{J}_{28}$ " from Albizia julibrissin. Glycoconjugate J. 2008, 25, 157; h) Zeng, Y.; Wang, Z.; Whitfield, D.; Huang, X. Installation of ElectronDonating Protective Groups, a Strategy for Glycosylating Unreactive Thioglycosyl Acceptors using the Preactivation-Based Glycosylation Method. J. Org. Chem. 2oo8, 73, 7952; i) Fridman, M.; Belakhov, V.; Lee, L. V.; Liang, F.-S.; Wong, C.-H.; Baasov, T. Dual Effect of Synthetic Aminoglycosides: Antibacterial Activity against Bacillus anthracis and Inhibition of Anthrax Lethal Factor. Angew. Chem. Int. Ed. 2005, 44, 447; Angew. Chem. 2005, $117,451$.

(4) a) Furneaux, R. H.; Ferrier, R. J. 1, 2-trans-1-Thioglycosides. Methods Carbohydr. Chem. 1980, 8, 251; b) Nicolaou, K. C.; Randall, J. L.; Furst, G. T. Stereospecific synthesis of rhynchosporosides, a family of fungal metabolites causing scald disease in barley and other grasses. J. Am. Chem. Soc. 1985, 107, 5556; c) Das, S. K.; Roy, J.; Reddy, K. A.; Abbineni, C. A mild and convenient indium(III) chloride-catalyzed synthesis of thioglycosides. Carbohydr. Res. 2003, 338, 2237; d) Tai, C.-A.; Kulkarni, S. S.; Hung, S.-C. Facile $\mathrm{Cu}(\mathrm{OTf})_{2}$-Catalyzed Preparation of Per-O-acetylated Hexopyranoses with Stoichiometric Acetic Anhydride and Sequential One-Pot Anomeric Substitution to Thioglycosides under Solvent-Free Conditions. J. Org. Chem. 2003, 68, 8719; e) Agnihotri, G.; Tiwari, P.; Misra, A. K. One-pot synthesis of per-O-acetylated thioglycosides from unprotected reducing sugars. Carbohydr. Res. 2005, 340, 1393.

(5) a) Fischer, E.; Delbruek, K. Über Thiophenol-glucoside. Ber. Dtsch. Chem. Ges. 1909, 42, 1476; b) Blanc-Muesser, M.; Defaye, J.; Driguez, H. Syntheses stereoselectives de 1-thioglycosides. Carbohydr. Res. 1978, 67, 305; c) Apparu, M.; Blanc-Muesser, M.; Defaye, J.; Driguez, H. Stereoselective syntheses of O- and Snitrophenyl glycosides. Part III. Syntheses in the $\alpha$-Dgalactopyranose and $\alpha$-maltose series. Can. J. Chem. 1981, 59, 314. (6) a) Brachet, E.; Brion, J.-D.; Messaoudi, S.; Alami, M. Stereoselective Palladium-Catalyzed Alkenylation and Alkynylation of Thioglycosides. Adv. Synth. Catal. 2013, 355, 2627; (b) Brachet. E; Brion, J.-B.; Messaoudi, S.; Alami, M. Palladium-Catalyzed Cross-Coupling Reaction of Thioglycosides with
(Hetero)aryl Halides. Adv. Synth. Catal. 2013, 355, 477; c) Bruneau, A.; Roche, M.; Hamze, A.; Brion, J.-D.; Alami, M.; Messaoudi, S. Stereoretentive Palladium-Catalyzed Arylation, Alkenylation, and Alkynylation of 1-Thiosugars and Thiols Using Aminobiphenyl Palladacycle Precatalyst at Room Temperature. Chem. Eur. J. 2015, 21, 8375; d) AL-Shuaeeb, R. A. A.; Montoir, D.; Alami, M.; Messaoudi, S. Synthesis of $(1 \rightarrow 2)$-S-Linked Saccharides and S-Linked Glycoconjugates via a Palladium-G3XantPhos Precatalyst Catalysis. J. Org. Chem. 2017, 82, 6720; e) Probst, N.; Lartia, R.; Théry, O.; Alami, M.; Defrancq, E.; Messaoudi, S. Efficient Buchwald-Hartwig-Migita Cross-Coupling for DNA Thioglycoconjugation. Chem. Eur. J. 2018, 24, 1795; f) Montoir, D.; Amoura, M.; Ababsa, Z. E.-A.; Vishwanath, T. M.; Yen-Pon, E.; Robert, V.; Beltramo, M.; Piller, V.; Alami, M.; Aucagne, A.; Messaoudi, S. Synthesis of ArylThioglycopeptides Through Chemoselective Pd-Mediated Conjugation. Chem. Sci., 2018, 9, 8753. g) Benmahdjoub, S.; Ibrahim, N.; Benmerad, B.; Alami, M.; Messaoudi S. One-Pot Assembly of Unsymmetrical Biaryl Thioglycosides through Chemoselective Palladium-Catalyzed Three-Component Tandem Reaction. Org. Lett. 2018, 20, 4067.

(7) Brachet, E.; Brion, J.-D.; Alami, M.; Messaoudi, S. Nickel-Catalyzed Arylation, Alkenylation, and Alkynylation of Unprotected Thioglycosides at Room Temperature. Chem. Eur. J. 2013, 19, 15276.

(8) (a) Nauš, P.; Lešetický, L.; Smrček, S.; Tišlerová, I.; Štícha, M. Copper-Assisted Arylation of 1-Thiosugars: Efficient Route to Triazene Substituted Arylthioglycosides. Synlett 2003, 14, 2117; b) Chabrier, A.; Bruneau, A.; Benmahdjoub, S.; Benmerad, B.; Belaid, S.; Brion, J.-D.; Alami, M.; Messaoudi, S. Stereoretentive Copper-Catalyzed Directed Thioglycosylation of C $\left(\mathrm{sp}^{2}\right)-\mathrm{H}$ Bonds of Benzamides. Chem. Eur. J. 2016, 22, 15006. c) Yuan, X.; Kou, Y.; Yu, L.; Zhang, Z.-X.; Xue, W. 2' -Cyanoethyl thioglycosides: effective nucleophiles for synthesis of (hetero)aryl thioglycosides under the catalysis of $\mathrm{Cu}$. Org. Chem. Front. 2015, 2, 1604.

(9) Fore a recent review, see: Ibrahim, N.; Alami, M.; Messaoudi, S. Recent Advances in Transition Metal-Catalyzed Functionalization of 1-Thiosugars. Recent Advances in Transition-MetalCatalyzed Functionalization of 1-Thiosugars. Asian. J. Org. Chem. 2018, 7, 2026.

(10) selected review, see: a) Prier, C. K.; Rankic, D. A.; MacMillan, D. W. C. Visible Light Photoredox Catalysis with Transition Metal Complexes: Applications in Organic Synthesis. Chem. Rev. 2013, 113, 5322; b) Twilton, J.; Le, C. (C.); Zhang, P.; Shaw, M. H.; Evans, R. W.; MacMillan, D. W. C. The merger of transition metal and photocatalysis. Nature Rev. Chem., 2017, 1, 0052 (c) Megan Shaw, H.; Twilton, J.; MacMillan, D. W. C. Photoredox Catalysis in Organic Chemistry. J. Org. Chem., 2016, 81, 6898; d) Gui, Y. Y.; Sun, L.; Lu, Z. P.; Yu, D. G. Photoredox sheds new light on nickel catalysis: from carbon-carbon to carbonheteroatom bond formation. Org. Chem. Front., 2016, 3, 522. e) Milligan, J. A.; Phelan, J. P.; Badir, S. O.; Molander, G. A. Alkyl Carbon-Carbon Bond Formation by Nickel/Photoredox Cross-Coupling. Angew. Chem. Int. Ed. 2019, 58, 6152.

(11) Oderinde, M. S.; Frenette, M.; Robbins, D. W.; Aquila, B.; Johannes, J. W. Photoredox Mediated Nickel Catalyzed CrossCoupling of Thiols With Aryl and Heteroaryl Iodides via Thiyl Radicals. J. Am. Chem. Soc. 2016, 138, 1760.

(12) Vara, B. A.; Li, X.; Berritt, S.; Walters, C. R.; Peterssona, E. J.; Molander, G. A. Scalable thioarylation of unprotected peptides and biomolecules under $\mathrm{Ni} /$ photoredox catalysis. Chem. Sci., 2018, 9, 336.

(13) Jouffroy, M.; Kelly, C.B. Molander, G. A. Thioetherification via Photoredox/Nickel Dual Catalysis. Org. Lett. 2o16, 18, 876. 
(14) For a detailed mechanistic analysis of photoredox/Ni dual catalysis. See: Gutierrez, O.; Tellis, J. C.; Primer, D. N.; Molander, G. A.; Kozlowski, M. C. J. Am. Chem. Soc. 2015, 137, 4896.

(15) Selected reviews: a) Knowles, J. P.; Elliott, L. D.; BookerMilburn, K. I. Flow photochemistry: Old light through new windows. Beilstein J. Org. Chem. 2012, 8, 2025; b) Su, Y.; Straathof, N. J. W.; Hessel, V.; Noël, T. Photochemical Transformations Accelerated in Continuous-Flow Reactors: Basic Concepts and Applications. Chem. Eur. J. 2014, 20, 10562; c) Garlets, Z. J.; Nguyen, J. D.; Stephenson, C. R. J. The Development of Visible-Light Photoredox Catalysis in Flow. Isr. J. Chem. 2014, 54, 351; d) Cambié, D.; Bottecchia, C.; Straathof, N. J. W.; Hessel, V.; Noël, T. Applications of Continuous-Flow Photochemistry in Organic Synthesis, Material Science, and Water Treatment. Chem. Rev. 2016, 116, 10276. 